\title{
Sleep and the Immune System
}

\author{
Daniel P. Cardinali ${ }^{*}, 1$ and Ana I. Esquifino ${ }^{2}$
}

\begin{abstract}
${ }^{1}$ Departamento de Docencia e Investigación, Facultad de Ciencias Médicas, Pontificia Universidad Católica Argentina, and Departamento de Fisiología, Facultad de Medicna, Universidad de Buenos Aires, Argentina
\end{abstract}

${ }^{2}$ Departamento de Bioquímica y Biología Molecular III, Facultad de Medicina, Universidad Complutense, Madrid, Spain

\begin{abstract}
From a physiological perspective the sleep-wake cycle can be envisioned as a sequence of three physiological states, identified by a particular homeostatic patent: wakefulness, non-rapid eye movement (NREM) or slow sleep, and REM sleep. These three physiological states are defined by a particular neuroendocrine-immune profile that regulates the immune system response. This review discusses the physiological basis of such a control of the immune system at different sleep stages, as well as the manner in which humoral signals (cytokines) produced by immunocompetent cells modify the mechanisms of sleep.
\end{abstract}

Keywords: Circadian rhythms, cytokines, melatonin, neuroimmunology, sleep.

\section{INTRODUCTION}

The association between sleep and the immune system was first identified in the 1970's, when a sleep-inducing factor was isolated and chemically characterized from human urine as a muramyl peptide derived from bacterial peptoglycan (or "Factor S") [1]. Subsequently muramyl dipeptide and Factor S-related peptidoglycans were all shown to induce the release of a key immunoregulatory cytokine, i.e. interleukin (IL)-1, a potent somnogen and central player in the physiological regulation of sleep. IL-1 levels in the brain correlate with sleep proneness [2] (Fig. 1).

Sleep and the immune system share regulatory molecules. These molecules, mostly cytokines, are involved in both physiological sleep and in the disturbed sleep observed during the acute-phase response to infection or in chronic inflammation. It is feasible that sleep influences the immune system through the action of centrally produced cytokines that are regulated during sleep (see for ref. [3]).

To examine the reciprocal relationships between sleep and the immune system, two approaches have been generally used. On one hand, human volunteers or laboratory animals have been sleep-deprived and the effects on selected immune parameters determined. On the other, laboratory animals and in some cases humans have been infected with pathogens or challenged with immunomodulators. It is now possible to conclude that sleep deprivation alters immune function and that any immune challenge will eventually alter sleep quality. The objective of the review is to summarize some of the mechanisms implicated in the mutual interaction between sleep and the immune system.

\section{SLEEP IS A COMPLEX PHENOMENON COMPRI- SING TWO SUB-STATES}

Sleep is an essential process in life. It is a behavioral state defined by: (i) characteristic relaxation of posture; (ii)

*Address correspondence to this author at the Departamento de Docencia e Investigación, Facultad de Ciencias Médicas, UCA, Av. Alicia Moreau de Justo 1500, $4^{\circ}$ Piso, C1107AFD Buenos Aires, Argentina; Tel/Fax: +54 11 43590200, Ext. 2310;

E-mails: danielcardinali@uca.edu.ar, danielcardinali@fibertel.com.ar raised sensory thresholds; (iii) distinctive electroencephalographic (EEG) pattern; and (iv) ready reversibility. One difficulty in understanding sleep is that it is not a unitary state but composed of two sub-states. Based on polysomnographic measures, sleep has been divided into categories of rapid eye movement (REM) sleep and nonREM (NREM) sleep (also called slow wave sleep) [4].

NREM sleep comprises four stages (stage 1 to stage 4), with stages 3 and 4 being characterized by slow, high amplitude EEG waves in the frequency range below $4-\mathrm{Hz}$ (delta rhythm). Sleep alternates between NREM stages 1-4 and REM sleep approximately every 90-120 min [5]. Periods of NREM sleep constitute about $80 \%$ of the total sleep time and NREM reaches its greatest depth during the first half of the night. After completion of fourth stage, the next stage does not begin immediately. Instead, the first four stages reverse quickly and are then immediately followed by a period of REM sleep.

REM sleep is defined by a faster EEG activity, rapid horizontal eye movements on electrooculography, vital sign instability and the occurrence of skeletal muscle hypotonia and dysautonomia. The tone in most voluntary muscles is minimal but the diaphragm and the eye muscles are phasically active, giving REM sleep some resemblance to the wake state, for which reason it is sometimes referred to as "paradoxical sleep".

The length of the NREM and REM stages is not static. The first REM sleep will occur roughly 90 min after falling asleep and will last only $10 \mathrm{~min}$. As night proceeds the length of stages 3 and 4 of NREM (delta or deep sleep) begins to wane and the length of REM sleep increases up to about $0.5 \mathrm{~h}$ in length after a number of cycles. After a prolonged period of wake activity (as in humans) the first cycles are characterized by a preponderance of high-voltage, slow wave activity (i.e., the NREM phase is enhanced) while the last cycles show more low-voltage, fast wave activity (i.e., the REM phase is enhanced) (Fig. 1) [6-8].

The recurrent cycles of NREM and REM sleep are accompanied by major changes in physiology. Indeed, it can be said that we live sequentially in three different physiological states ("bodies"): that of wakefulness, that of 


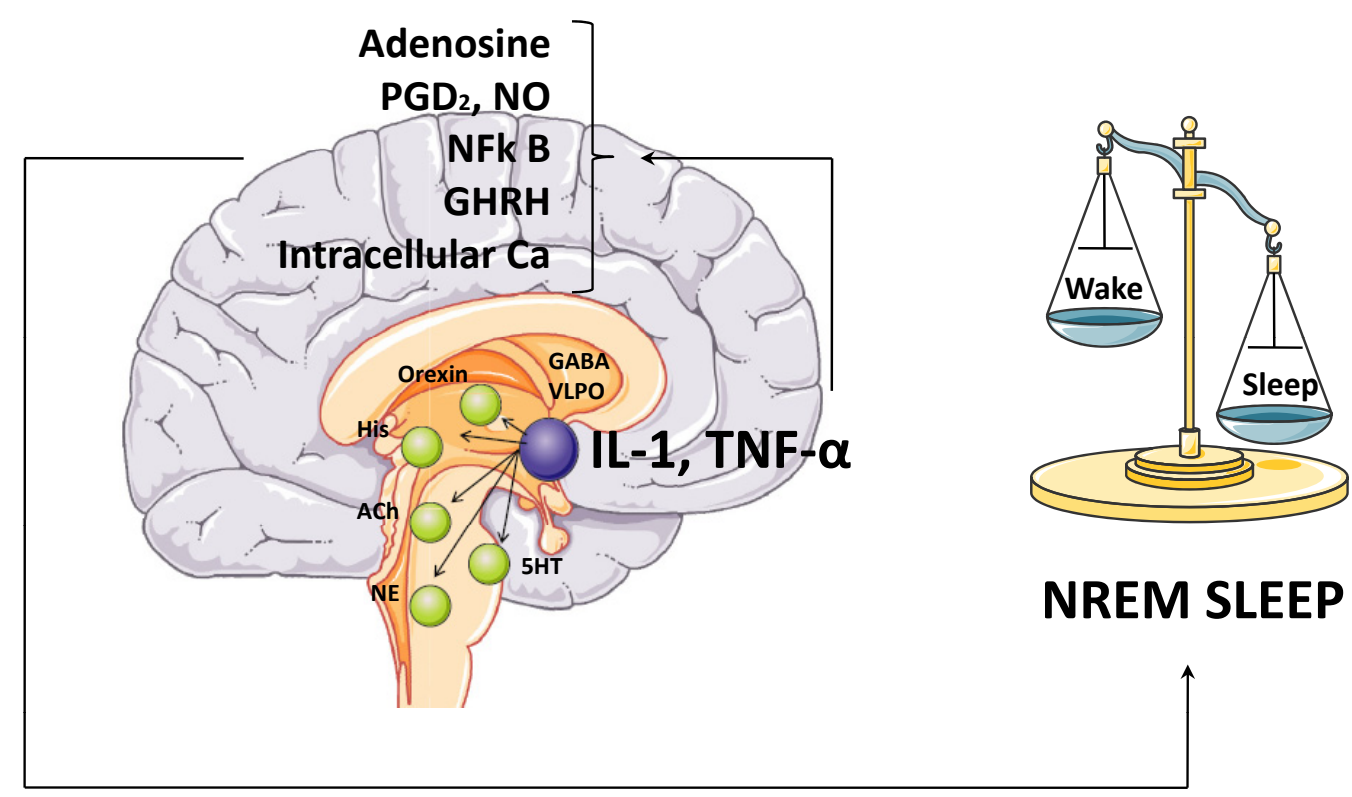

Fig. (1). The increase in IL-1 and TNF- $\alpha$ in the anterior hypothalamus as a result of wakefulness-related neuronal/glial mechanisms activates the activity of the ventrolateral preoptic area (VLPO). This increase in cytokines constitutes the biochemical correlate of the "sleep debt" (S process). The cascade of events triggered include adenosine, growth hormone releasing hormone (GHRH), NOS, PGE $2, \mathrm{Ca}^{2+}$ and other components of the signaling mechanisms leading to activation of NF $\kappa \mathrm{B}$. VLPO plays a critical role in sleep initiation and maintenance. $\gamma$ Aminobutyric acid (GABA) is the primary inhibitory neurotransmitters of the VLPO. This nucleus sends out multiple inhibitory projections that innervate neurons that release wake-promoting neurotransmitters, including orexin neurons in the lateral and posterior hypothalamic areas, NE neurons in the locus coeruleus, histamine neurons in the tuberomammillary nuclei, serotonin (5HT) in raphe nuclei and acetilcholine (Ach) in laterodorsal/pedunculopontine tegmental nuclei. VLPO fires at a rapid rate during sleep with substantial attenuation of firing during wakefulness. Likewise, neurons in wake-promoting centers fire rapidly during wakefulness and are relatively quiescent during sleep, with the exception of the cholinergic neurons, which fire rapidly during REM sleep. It is through this reciprocal interplay of stimulation and inhibition that stable states of sleep and wakefulness are maintained.

NREM sleep and that of REM sleep. For an average of $8 \mathrm{~h}$ of sleep per day, a 76-years-old adult has lived about 50 years in wakefulness, 20 years in NREM sleep and 6 years in REM sleep. Since most epidemiological data indicate that in our modern society we indulge only about $6 \mathrm{~h}$ of sleep per day, for an adult living 76 years, approximately 55 years are lived in wakefulness, 15 years in NREM sleep and 6 years in REM sleep [6,7]. There is an increasing evidence that obesity, metabolic syndrome and neurodegenerative diseases can be related to the prevalence of wakefulness in face of sleep loss in contemporary, 24/7 Society [8-10].

As shown in Table 1, significant physiological differences exist among the three physiological stages above discussed. Wakefulness is a catabolic, sympathotonic stage as reflected in every physiological system examined with a predominant activity of the hypothalamic-pituitary axis (HPA) and high cortisol and norepinephrine levels, whereas NREM sleep is a anabolic stage characterized by a parasympathetic predominance, with decreases in blood pressure, heart rate, and respiratory rate, and occurrence of a pulsatile release of anabolic hormones like growth hormone $(\mathrm{GH})$, insulin and prolactin. Indeed, NREM sleep is functionally associated with several cytoprotective processes and in the brain several neurotrophic factors are synthesized during this period [11-13].

REM sleep is typically an "antihomeostatic" stage (Table 1). The regulatory mechanisms controlling cardiovascular, respiratory and thermoregulatory functions become grossly inefficient, leaving functional the spinal, metameric responses only. Heart rate and blood pressure as well as their variability increase and the respiratory rate becomes irregular [7]. Awakening from REM sleep typically yields reports of hallucinoid dreaming, even in subjects who rarely or never recall dreams spontaneously. This indicates that the brain activation of this phase of sleep is sufficiently intense and organized to support complex mental processes and again argues against a rest function for most of the brain in REM. Indeed, several areas of the brain, e.g. the limbic system, are more active in REM than during wakefulness [14].

A significant physiological concomitant of REM sleep is the loss of temperature regulation. If ambient or core temperature begins to fall during REM sleep, thermoregulatory processes cannot be brought into play and body temperature falls. Thus the notion that we humans are homeothermic animals is not correct. The evolutionary logic of somatic and autonomic disconnection during REM is that if acted, this period of sleep could be damaging for individual's survival.

\section{THE SLEEP/WAKE CYCLE IS THE MOST RELE- VANT 24-HOUR CYCLE}

In mammals, the circadian system is composed of many individual, tissue-specific cellular clocks [15]. To generate coherent physiological and behavioral responses, the phases of this multitude of cellular clocks are orchestrated by a master circadian pacemaker residing in the suprachiasmatic nucleus (SCN) of the anterior hypothalamus [16]. The 
sleep/wake cycle is the most prominent circadian rhythm in humans.

At a molecular level, circadian clocks are based on clock genes, some of which encode proteins able to feedback and inhibit their own transcription. These cellular oscillators consist of interlocked transcriptional and post-translational feedback loops that involve a small number of core clock genes (about 12 genes identified currently) [17]. The positive drive to the daily clock is constituted by two, basic helixloop-helix, PAS-domain containing transcription factor genes, called Clock and Bmal1. The protein products of these genes form heterodimeric complexes that control the transcription of other clock genes, notably three Period (Per1/Per2/Per3) genes and two Cryptochrome (Cry1/Cry2) genes, which in turn provide the negative feedback signal that shuts down the Clock/Bmal drive to complete the circadian cycle [18].

Per and Cry messenger RNAs peak in the SCN in mid-tolate circadian day, regardless of whether an animal is nocturnal or diurnal. Other clock genes provide additional negative and positive transcriptional/translational feedback loops to form the rest of the core clockwork, which has been characterized in rodents by a transgenic gene deletion methodology. Clock gene expression oscillates because of the delay in the feedback loops, regulated in part by phosphorylation of the clock proteins that control their stability, nuclear re-entry and transcription complex formation $[19,20]$.

Two interacting processes are interlocked to regulate the timing, duration and depth, or intensity, of the circadian sleep/wake cycle $[21,22]$ : a homeostatic process (S process, for sleep) that maintains the duration and intensity of sleep within certain boundaries and a circadian component (C process, for circadian) that determines the timing of sleep. In addition an ultradian rhythm of 90-120 min drives NREM sleep - REM sleep alternancy.

The S process depends on the immediate history: the interval elapsed since the previous sleep episode and the intensity of sleep in that episode; it controls mainly NREM sleep. The drive to enter sleep increases, possibly exponentially, with the time elapsed since the end of the previous sleep episode. The increase in IL-1 and TNF- $\alpha$ in the anterior hypothalamus as a result of wakefulness-related neuronal/glial mechanisms constitutes the biochemical correlate of the "sleep debt" (Fig. 1). This debt declines exponentially once sleep is initiated. The cyclical nature of sleep and wakefulness equates sleep with other physiological needs such as hunger or thirst [23, 24].

The $\mathrm{C}$ process, the circadian component, controls REM sleep via the master oscillator located in the SCN. The circadian system is also known as a wake-promoting system because it determines the timing and strength of wakefulness [21]. The circadian rhythm in the secretion of the pineal hormone melatonin has been shown to be responsible for the sleep rhythm in both normal and blind subjects (i.e., in the absence of the synchronizing effect of light). More specifically, it has been demonstrated that melatonin feedback at the SCN inhibits the circadian signal responsible for promoting wakefulness [25-27].
Studies in humans under constant routine conditions have led to the definition of the so-called "biological night" that corresponds to the period during which melatonin is produced and secreted into the bloodstream. The beginning of the biological night is characterized by onset of the melatonin surge, an accompanying increase in sleep propensity as well as a decrease in core body temperature; the opposite occurs as the biological night and sleep end [28]. Rising nocturnal levels of endogenous melatonin contribute significantly to the nocturnal decline in core body temperature. The inability to fall asleep during the "wake maintenance zone" or "sleep forbidden zone", occurs just prior to the opening of the "sleep gate" [29]. The sleep gate is represented by the steep rise in sleepiness that occurs during the late evening and that begins a period characterized by a consistently high degree of sleep propensity. The nocturnal onset of melatonin secretion predictably precedes the opening of the sleep gate by about $2 \mathrm{~h}$ and it is believed to initiate a cascade of events culminating 1-2 $\mathrm{h}$ later in the "opening of the sleep gate" [27]. Taken together, current findings suggest that the endogenous nocturnal circadian melatonin signal is involved in the circadian rhythm of sleep propensity by turning off the circadian wakefulnessgenerating mechanism rather than by actively inducing sleep.

\section{VIRTUALLY ALL IMMUNOLOGICAL VARIABLES DISPLAY CIRCADIAN PERIODICITY}

The $24 \mathrm{~h}$ sleep/wake rhythm correlates with specific circadian patterns of immune responses (Tables 1-3) [30, 31]. NREM sleep is associated with $\mathrm{T}$ helper (Th) 1 responses while during wakefulness Th2 responses are predominant. Th1 cells release mainly interferon- $\gamma($ IFN- $\gamma$ ), aside from other cytokines including IL- 2 and TNF- $\alpha$; they become activated in response to intracellular viral and bacterial challenges supporting cellular (type 1) responses, like macrophage activation and antigen presentation. Wakefulness is associated with predominance of cytokines characteristic of Th2 immunity e.g. IL-4, IL-5, IL-10 and IL13 , that mediate humoral (type 2) defense via stimulating mast cells, eosinophils and B cells against extracellular pathogens [31-33].

Indeed type 1-type 2 cytokine balance is crucial for the control of immune function, with type 1 cytokines overall supporting cellular aspects of immune responses and type 2 cytokines moderating the type 1 response [34, 35]. An excessive production of either cytokine type leads to inflammation and tissue damage on the one hand, and to susceptibility to infection and allergy on the other hand. To prevent overactivity, the type 1-type 2 cytokine balance is tightly regulated by mutual inhibition and via a complex neuroendocrine control.

The clinical relevance of the balancing function of sleep is indicated by the findings of an increased type 2-mediated allergic skin reaction after sleep deprivation in patients with atopic dermatitis [36]. Also, sleep deprivation after inoculation suppresses antibody responses to hepatitis A virus and influenza vaccinations [36-38].

Several reports indicate that the shift towards Th1 mediated immune defense occurring in NREM sleep is driven by the neuroendocrine environment (see for ref. [2, 
Table 1. The Three Physiological States ("Bodies") of Our Life

\begin{tabular}{|c|c|c|c|}
\hline & "Active brain in an active body" & "Inactive brain in an active body" & $\begin{array}{l}\text { "Hallucinating brain in a paralyzed } \\
\text { body" }\end{array}$ \\
\hline Neurochemical "microclimate" & $\begin{array}{l}\text { Tonic firing of neurons in the locus } \\
\text { coeruleus (noradrenergic) and raphe } \\
\text { nuclei (serotonergic) driven by } \\
\text { orexinergic hypothalamic neurons. } \\
\text { Phasic discharge of the pedunculo- } \\
\text { pontine nucleus of the pontine } \\
\text { tegmentum, PPT (cholinergic) }\end{array}$ & $\begin{array}{c}\text { Inhibition by VLPO area of the arousal } \\
\text { systems. Decreased aminergic activity in } \\
\text { face of progressive increase of } \\
\text { cholinergic activity (tonic firing of PPT } \\
\text { neurons). Both responsible for decreased } \\
\text { consciousness }\end{array}$ & $\begin{array}{c}\text { Prevalent cholinergic activity (PPT } \\
\text { nucleus) concomitant with extreme } \\
\text { reduction of aminergic activity. REM } \\
\text { sleep and wakefulness are states of } \\
\text { cortical activation with different } \\
\text { neuromodulationg pattern (cholinergic } \\
\text { vs noradrenergic) and different contents } \\
\text { of consciousness }\end{array}$ \\
\hline Afferent & $\begin{array}{l}\text { Actively functioning. Thalamocortical } \\
\text { circuit in "open gate fashion" so that } \\
\text { sensory information can reach the } \\
\text { cerebral cortex. Activated dorsolateral } \\
\text { prefrontal cortex (working memory) }\end{array}$ & $\begin{array}{l}\text { Thalamo-cortical circuit in "gate closed } \\
\text { fashion" (which prevents sensory } \\
\text { information to reach the cerebral cortex. } \\
\text { 25\% Decrease in cerebral blood flow and } \\
\text { oxygen consumption. Synthesis of } \\
\text { neurotrophins }\end{array}$ & $\begin{array}{c}\text { Thalamic activity changes to operation } \\
\text { "open gate fashion" as during } \\
\text { wakefulness }\end{array}$ \\
\hline Content awareness & Attention, logical thinking, memory & Disconnection, episodic memory & $\begin{array}{l}\text { Dream activity characterized by vivid } \\
\text { hallucinations, illogical thinking and } \\
\text { intense emotion }\end{array}$ \\
\hline Perception & Externally generated & Absent & $\begin{array}{l}\text { Generated internally, preferential } \\
\text { activation of the pons and limbic system } \\
\text { with deactivation of dorsolateral } \\
\text { prefrontal cortex }\end{array}$ \\
\hline $\begin{array}{c}\text { Physiological pattern in organs } \\
\text { and systems }\end{array}$ & $\begin{array}{c}\text { Predominance of sympathetic activity in } \\
\text { organs and systems, e.g., Th2 responses. } \\
\text { Augmented plasma norepinephrine and } \\
\text { cortisol }\end{array}$ & $\begin{array}{c}\text { Parasympathetic hyperfunction in organs } \\
\text { and systems. GH, prolactin and insulin } \\
\text { secretion. Th1 responses }\end{array}$ & $\begin{array}{l}\text { Generalized disconnection of } \\
\text { autonomic regulatory system (this } \\
\text { prevents expression of dreaming's } \\
\text { emotions). Antihomeostatic physiology }\end{array}$ \\
\hline
\end{tabular}

$33,39])$. The circadian peak of the ratio of IFN- $\gamma /$ IL-10 in whole blood samples during nocturnal sleep is abolished by administering glucocorticoids the preceding evening. Thus, the suppression of endogenous cortisol release and the increase in melatonin secretion, both driven by the SCN during early sleep, seems to play a promoting role for Th1 shift. In addition, NREM sleep that is dominant during the early part of nocturnal sleep promotes the release of $\mathrm{GH}$ and prolactin (Table 1) which supports Th1 cell-mediated immunity. In summary, $\mathrm{GH}$, prolactin and melatonin are known to shift the type 1-type 2 balance toward type 1, whereas cortisol and norepinephrine can shift it toward type $2[32,33]$.

Many studies have described circadian variations in immune parameters such as lymphocyte subpopulations, proliferation, antigen presentation, and cytokine gene expression [17, 40]. The number of lymphocytes and monocytes in the human blood reach maximal values during the night and are lowest after waking (Table 2). Natural killer (NK) cells, by contrast, reach their highest level in the afternoon, with a normal decrease in number and activity around midnight [41-43]. Changes in lymphocyte subset populations can depend on time of day-associated changes in cell proliferation of immunocompetent organs and/or on diurnal modifications in lymphocyte release and traffic among lymphoid organs.
Table 2. Maxima in 24-h Rhythm of Different Cell Populations in Healthy Volunteers

\begin{tabular}{|c|c|}
\hline Variable & Maximum at \\
\hline \hline Total leukocyte & $2200-2300 \mathrm{~h}$ \\
\hline Neutrophils, total & $1830-2030 \mathrm{~h}$ \\
\hline Neutrophils, adults & $1800-2000 \mathrm{~h}$ \\
\hline Neutrophils, bands & $1700-2000 \mathrm{~h}$ \\
\hline Lymphocytes & $0000-0200 \mathrm{~h}$ \\
\hline Monocytes & $0100-0300 \mathrm{~h}$ \\
\hline Eosinophils & $0100-0330 \mathrm{~h}$ \\
\hline Basophils & $1900-0200 \mathrm{~h}$ \\
\hline T lymphocytes (OKT3 ${ }^{+)}$ & $0000-0400 \mathrm{~h}$ \\
\hline T-helper lymphocytes (OKT4 ${ }^{+)}$ & $0000 \mathrm{~h}$ \\
\hline T-suppressor-cytotoxic (OKT8 + ) & $2030 \mathrm{~h}$ \\
\hline T-helper/T- cytotoxic & $0030-0430 \mathrm{~h}$ \\
\hline NK & $1800-1900 \mathrm{~h}$ \\
\hline Activated T Cells & $2030-0300 \mathrm{~h}$ \\
\hline Activated B cells & $1150 \mathrm{~h}$ \\
\hline B cells (Slg +) & $2000 \mathrm{~h}$ \\
\hline Pre-B Lymphocytes & $1350 \mathrm{~h}$ \\
\hline Light chain B cells & $0900 \mathrm{~h}$ \\
\hline
\end{tabular}


In view of their significant circadian changes, immune cells have been tested for the presence of clock genes [40, 44-48]. In a study aimed to investigate whether circadian clock genes function in human peripheral blood mononuclear cells, clock genes Per1, Per2 and Per3 were found to be expressed in a circadian manner in human peripheral blood mononuclear cells, with the a peak level occurring during the second part of the active phase $[49,50]$. The presence of molecular clock mechanisms in NK cells conjointly with the circadian expression of critical factors involved in NK cell function were verified by demonstrating the 24-h expression of clock genes (Per1, Per2, Bmal1, Clock), Dbp (a clock-controlled output gene), CREB (involved in clock signaling), cytolytic factors (granzyme B and perforin), and cytokines IFN- $\gamma$ and TNF- $\alpha$ in NK cells enriched from the rat spleen [51]. Thus, the existence of a molecular clock machinery seems to be conserved across different lymphocyte subsets and peripheral blood cells. Moreover, they may share common entrainment signals.

Rhythms in the number of circulating $\mathrm{T}$ cells persisted in rats with disrupted circadian output [52] and SCN ablation did not affect the 24-h rhythms in cell cycle phase distribution in bone marrow cells [53]. These observations suggest that some rhythms in the immune system are SCNindependent. Entrainment signals other than light can be coordinating the rhythm in $\mathrm{NK}$ cell function and other immunological parameters. For example, feeding is an important synchronizer for peripheral clock gene expression [52], and the internal desynchronization produced by restricted feeding during the light period can slow down tumor progression in mice [54]. Daily locomotor activity rhythms are also considered to act as entrainment cues for peripheral tissues [55] and may as well influence the molecular clock in lymphocyte cells. In addition, intrinsic immunological outputs such a cytokine secretion could function as entrainment factors for immune cells. Indeed, IL6 has been shown to induce Per1 expression in vitro [56].

Several studies have investigated the changes in cytokine levels that occur during the $24 \mathrm{~h}$ sleep-wake cycle in humans (Table 3) (for references see [3, 33]). Plasma TNF- $\alpha$ levels peak during the dark phase of cycle, and this circadian rhythm of TNF- $\alpha$ release is disrupted by sleep pathology, e.g. obstructive sleep apnea. Plasma IL-1 $\beta$ levels also have a diurnal variation, being highest at the onset of NREM sleep. Both intrahypothalamic IL- 1 and TNF- $\alpha$ regulate sleep (Fig. 1).

The levels of other cytokines (including IL-2, IL-6, IL-10 and IL-12) and the proliferation of $\mathrm{T}$ cells in response to mitogens also change during the 24 -h cycle. The production of macrophage-related cytokines (such as TNF- $\alpha$ ) increases during sleep (in response to in vitro stimulation) in parallel with the rise in monocyte numbers in the blood. The production of T-cell-related cytokines (such as IL-2) increases during sleep, independent of migratory changes in T-cell distribution $[3,33]$. All of these diurnal changes could be specific to the effects of sleep or associated with the circadian oscillator. To dissociate both effects, experimental procedures such as forced desynchrony are needed.

In our laboratory we have examined the regulation of circadian rhythmicity of lymph cell proliferation in a number of experimental models in rats using the submaxillary lymph nodes. The bilateral anatomical location of submaxillary lymph nodes and their easily manipulable autonomic innervation allowed us to dissect the humoral and neural mechanisms regulating the lymphoid organs and their interaction. A significant diurnal variation of rat submaxillary lymph node cell proliferation was uncovered, displaying maximal activity at early afternoon [57]. Such a maximum coincided with peak mitotic responses to lipopolysaccharide (LPS) and concanavalin A. A purely neural pathway including as a motor leg the autonomic nervous system innervating the lymph nodes was identified [58]. The combined sympathetic-parasympathetic denervation of the lymph node suppressed circadian variation in lymph cell proliferation. In addition, a hormonal pathway involving the circadian secretion of melatonin also plays a role to induce rhythmicity [59].

Table 3. Maxima in 24-h Rhythm of Some Circulating Cytokines and Antibodies in Healthy Volunteers

\begin{tabular}{|c|c|}
\hline Variable & Maximum at \\
\hline \hline IL-1 & $1300 \& 0030 \mathrm{~h}$ \\
\hline IL-10 & $1830 \mathrm{~h}$ \\
\hline IL-2 & $0100 \mathrm{~h}$ \\
\hline IL-6 & $2200 \mathrm{~h}$ \\
\hline IL-10 & $0730 \& 1930 \mathrm{~h}$ \\
\hline IL-12 & $1800 \mathrm{~h}$ \\
\hline IFN $\gamma$ & $0230 \mathrm{~h}$ \\
\hline TNF- $\alpha$ & $0300 \mathrm{~h}$ \\
\hline IgA & $1200-1500 \mathrm{~h}$ \\
\hline IgG & $1400-1600 \mathrm{~h}$ \\
\hline IgM & $1500-1800 \mathrm{~h}$ \\
\hline IgE in asthma & $0730-1600 \mathrm{~h}$ \\
\hline C3 Complement & $1200-1930 \mathrm{~h}$ \\
\hline C-reactive protein in rheumatoid arthritis & $2330 \mathrm{~h}$ \\
\hline
\end{tabular}

In the last years a number of studies have started to unravel the basis for the circadian modulation by immune factors on the circadian system itself (for ref. see [60]). Several reports indicate a possible immune feedback regulation of the circadian clock. For example, immunosuppressant drugs such as cyclosporine affect the phase of locomotor activity [61] and of hormone secretion $[62,63]$. Moreover, immune-related transcription factors are present and active in the SCN and its activity is partially necessary for light-induced phase shifts [61].

\section{THE CIRCADIAN SIGNAL MELATONIN IS INVOLVED IN IMMUNOMODULATION}

The endogenous pineal melatonin signal, which serves as an important physiological modulator of sleep, can affect a wide array of immune functions [64]. In fact, there is a tight correlation between the nocturnal production of melatonin 
and the nocturnal rise in circulating $\mathrm{T}$ lymphocytes while a reduction in endogenous melatonin production leads to immune suppression. This occurs via a reduction in lymphocytes such as NK cells and cytotoxic tumor infiltrating lymphocytes as well as a decrease in the production, by circulating immune cells, of a number of cytokines like IL-2, IL-12, IFN- $\gamma$ and TNF- $\alpha$. Also at physiological nocturnal circulating concentrations, melatonin can reduce the production of IL-10 and activate that of IL- 6 .

The immunomodulatory role of melatonin is related in part to its action on specific melatonin receptors located in immunocompetent cells [27]. In a study on two human lymphocytic and monocytic cell lines the addition of melatonin was found to enhance IL- 2 and IL- 6 production by acting primarily through nuclear ROR $\alpha$ receptors [65]. Melatonin synthesized by human lymphocyte may play a role in modulating the IL-2/IL-2 receptor system, as indicated by studies showing that when melatonin biosynthesis is blocked, both IL-2 and IL-2 receptor levels fall, an effect counteracted by the addition of exogenous melatonin [66]. Similarly, prostaglandin (PG) $E_{2}$-induced inhibition on IL-2 production increased when melatonin membrane receptors were blocked. Taken together, these data indicate that melatonin synthesized in human lymphocytes is involved in the physiological regulation of the IL-2/IL-2R expression through a mechanism comprising both membrane and nuclear melatonin receptors [66].

The contribution of $\mathrm{MT}_{1}$ and $\mathrm{MT}_{2}$ receptors in mediating the melatonin-induced enhancement of cellular and humoral immune function was explored in mice [67]. Melatonin enhanced splenocyte proliferation in wild type and $\mathrm{MT}_{1}$-/mice, an effect that was blocked by the melatonin receptor blocker luzindole, indicating that the melatonin-induced enhancement of immune function is mediated via $\mathrm{MT}_{2}$ receptors [67].

A number of studies support the immunoregulatory action of melatonin on innate immunity. Melatonin stimulates the production of progenitor cells for granulocytes and macrophages (GM-CFU) and has a general stimulatory action on hemopoiesis [66]. Melatonin receptors are detectable in monocyte/macrophage lineage and melatonin binding to both membrane and nuclear receptors stimulates the production of GM-CFU cells [66]. Exogenous melatonin augments NK cells and monocytes in both the bone marrow and the spleen with a latency of 7 to 14 days. The action of melatonin on monocyte production can be partly due to its direct action on melatonin receptors or may be due to an increase of monocyte sensitivity to stimulants like IL-3, IL4, IL-6 or GM-colony stimulating factor (GM-CSF) [68]. Melatonin increases the actual production of GM-CSF cell lineage but not the inter-organ trafficking of myeloid precursors [68]. An increased activation of monocytes/macrophages by melatonin has also been reported in another study in rodents [69]. As both macrophage cells and neutrophils form important components of the innate immune system, the stimulatory action of melatonin reflects a significant immunoenhancing property.

The time course of the innate immunological response involves a pro-inflammatory phase followed by an antiinflammatory phase. Pro-inflammatory responses serve as a defense against several stressor conditions, and sequential processes that shut down these responses are necessary to avoid exacerbation or the development of chronic diseases. It has been proposed that melatonin plays a role in both phases of the inflammatory response, both after release from the pineal gland as well as by the release from activated mononuclear and polymorphonuclear cells in a paracrine manner at the site of injury [70,71].

The immunostimulatory role of melatonin is exerted mainly on Th cells and on T lymphocyte precursors [72, 73]. The possibility exists that melatonin could act as an autacoid in bone marrow as shown by the demonstration of melatonin synthesis in bone marrow cells of mice and humans [74]. Melatonin augments $\mathrm{CD} 4^{+}$lymphocytes and decreases $\mathrm{CD} 8^{+}$ lymphocytes in submaxillary lymph nodes [75]. Collectively, published studies indicate that melatonin possesses important immunoenhancing properties and suggest that melatonin may favor mainly a Th-1 response, for example, during the natural history of human immunodeficiency virus type I infection [76].

In addition, orally administered melatonin can substantially promote the survival (anti-apoptosis) of precursor B lymphocytes (responsible for humoral immunity) in the B lymphocyte generating site, i.e., the bone marrow [77]. This indicates that melatonin treatment can boost the survival of mature B cells which are the functional elements in humoral immunity.

\section{SLEEP DEPRIVATION STUDIES PROVIDE CLUES ON THE IMMUNOREGULATORY EFFECT OF SLEEP}

Sleep deprivation is associated with a shift of the type 1type 2 cytokine balance toward type 2 activity, as found in healthy subjects acutely deprived of sleep and in chronic sleep deficits occurring in insomnia, alcoholism, stress and during the course of aging [33]. A consistent finding is that pro-inflammatory cytokines are elevated in all these groups [78-80]. Sleep apneics and narcoleptics have higher TNF- $\alpha$ levels compared to controls while abstinent alcoholics and people partially deprived of sleep show elevations of both TNF- $\alpha$ and IL-6. Together with increased levels of inflammatory cytokines, insomniacs show decreased $\mathrm{T}$ helper $\left(\mathrm{CD}^{+}, \mathrm{CD}^{+}\right)$, T-cytotoxic $\left(\mathrm{CD}^{+}\right)$cell numbers and decreased NK cell activity [78, 81]. Experimentally-induced sleep deprivation has been found to alter the diurnal pattern of cellular and humoral immune functions [82-84] and to decrease overall immune function [84] in normal adults.

IL-6 is one of the cytokines whose levels fluctuate in response to partial sleep deprivation. IL-6 is produced by multiple sources including monocytes, fibroblasts, endothelial cells, smooth muscle cells, and adipose tissue [85]. IL-6 regulates systemic inflammation by stimulating production of acute phase reactants by the liver. It also stimulates both B-cell maturation into plasma cells and $\mathrm{T}$ cell differentiation to cytotoxic $\mathrm{T}$ cells. Elevated levels of plasma IL-6 are associated with polyarthritis and rheumatoid arthritis [85].

IL-6 has a circadian rhythm, peaking at night, with lower levels during the day. In healthy men, the levels of IL-6 increased with peak values occurring $2.5 \mathrm{~h}$ after sleep onset [84]. During partial sleep deprivation, the nocturnal increase 
of IL-6 was delayed and did not occur until sleep was allowed. Hence, like GH secretion, sleep, rather than a circadian pacemaker, influences nocturnal IL-6 secretion [84].

To study the role of nocturnal sleep on normal immune regulation in a design to assess acute sleep loss rather than excessive sleep loss, normal volunteers slept two consecutive regular sleep-wake cycles or remained awake for 24 hours followed by recovery sleep [86, 87]. No alteration in the absolute production of IL- $1 \beta$ and TNF- $\alpha$ between the two experimental conditions was found; however, the expected decrease of IL- $1 \beta$ and TNF- $\alpha$ during sleep was blocked when subjects were kept awake. Hence, there was an increase in the nocturnal production of both cytokines during the sleep deprivation period. Other studies evaluating sleep restriction, found a delayed nocturnal release of sleep-associated cytokines, IL-1, IL-6 and TNF- $\alpha$, with subsequent recuperation of normal levels on recovery nights $[84,85$, 88]. This suggests that cytokines depend more on the activity of the sleep homeostat than on the circadian oscillator.

Deep sleep has an inhibitory influence on the hypothalamic-pituitary-adrenal (HPA) axis, in contrast to activation of the HPA axis or administration of glucocorticoids, which has been reported to lead to arousal and sleeplessness [32]. Not surprisingly then, insomnia, the most common sleep disorder, is associated with a 24-hour increase of corticotropin and cortisol secretion, consistent with a disorder of CNS hyperarousal. Clearly sleep deprivation, by removing the prevalent parasympathetic component of NREM sleep (Table 1), co-exists with the activation of the HPA with elevated glucocorticoid and catecholamine plasma levels [32,89].

However, the level of activation varies and normal levels of cortisol are detectable in the morning after a night of sleep deprivation, the rise becoming evident in the next evening following sleep deprivation [90]. What happens is that the amplitude of cortisol circadian rhythm decreased significantly. In animal studies, in which sleep deprivation is more intense, the elevation of corticosterone and catecholamine levels is prominent [91].

There are some differences between sleep deprivation and stress responses. Hu et al. examined serum cytokine and chemokine levels following $36 \mathrm{~h}$ of sleep deprivation, or after exposure to a known physical stressor (rotational stress) [92]. Changes in inflammatory cytokines/chemokines were observed following each manipulation, but the qualitative and quantitative patterns differed in the two scenarios. Only physical stress was associated with increases in serum corticosterone levels, and with independent evidence (using in vitro immune allo stimulation) for a generalized immunosuppression secondary to the experimental manipulation [92]. Altered cytokine production following sleep perturbation may thus occur via a different mechanism from that attributed to stress per se.

\section{CYTOKINES HAVE AN ACTIVE ROLE IN SLEEP REGULATION}

The criteria to be fulfilled for a presumed sleep regulatory molecule were proposed by Krueger and coworkers as: "(1) the molecule should induce physiological sleep; (2) the substance and its receptors should be present in the organism; (3) the concentration or turnover of the substance or its receptor should vary with the circadian rhythm; (4) induction of the substance should induce sleep; (5) inactivation of the substance or its receptor should reduce spontaneous sleep; (6) inactivation of the substance should reduce sleep induced by somnogenic stimuli; and (7) other biological actions of the substance should be separable, in part, from its sleep-promoting actions" [2].

Cytokines as immune-mediators match those criteria. They are multifunctional pleiotropic proteins that are involved not only in the immune response but also in a variety of physiological and pathological processes in the CNS [93-95].

Cytokines exert their effect on the CNS both directly and indirectly. Direct action means that cytokines themselves are present in the brain, in and/or around the various neuronal and glial cells, while secondary effects that are the result of cytokine action on other targets represent the indirect pathways. The various cytokines directly affecting the CNS have two possible origins, namely the periphery and the brain. As large, hydrophilic proteins, cytokines can only cross the blood-brain barrier at leaky points (the circumventricular organs) or via specific active transport mechanisms. Cytokines act at the level of the organum vasculosum laminae terminalis, a circumventricular organ located at the anterior wall of the third ventricle. IL-1 binds to cells located on the vascular side of this circumventricular structure, thereby inducing synthesis and release of second messenger systems, such as nitric oxide (NO) synthase (NOS)/NO and the cyclooxygenase/PG systems. It must be noted that a central compartment for cytokines exists and that there are data indicating that an increase in peripheral cytokines evokes a mirror increase in brain levels of cytokines [2]. Cytokines that originate in peripheral immune organs can also affect sensory peripheral autonomic terminals, even in healthy, basal conditions.

A variety of physical or psychological stimuli activates the production of proinflammatory cytokines and that of other inflammatory mediators both in the immune system and the CNS [33]. Physical stimuli (e.g. infections) induce cytokine production usually in the periphery and their effect on sleep and on the CNS prevail via the various mechanisms above enumerated. These cytokines also promote the production of each other, change the level of stress hormones and are under the regulation of the HPA axis [2]. These interactions might be either synergistic or attenuated, and result in somnogenic and anti-somnogenic effects (Table 4).

Imbalances in the effects of somnogenic and antisomnogenic cytokines can be involved in sleep disturbances. Of the cytokines in the sleep producing group, the most extensively studied and best established are IL-1 $\beta$ and TNF$\alpha$, proinflammatory cytokines that produce fever in addition to sleep. The febrile effects of these cytokines can be blocked without altering their soporific actions.

Besides having circadian rhythms with similar nocturnal peaks, TNF- $\alpha$ and IL- $1 \beta$ seem to act cooperatively in animals to prolong NREM sleep (Fig. 1). Although the exact mechanisms of the somnogenic or anti-somnogenic effects of cytokines have not yet been fully elucidated, the cascade 
has also been shown to involve other factors, such as adenosine, growth hormone releasing hormone (GHRH), NOS, PG like $\mathrm{PGE}_{2}, \mathrm{Ca}^{2+}$ and other components of the signaling mechanisms leading to activation of the transcription nuclear factor $(\mathrm{NF}) \kappa \mathrm{B}[2,96]$ (Fig. 1).

Table 4. Cytokines Active on Sleep

\begin{tabular}{|c|c|}
\hline Prosomnogenic Cytokines & Antisomnogenic Cytokines \\
\hline \hline IL-1 & IL-4 \\
\hline TNF- $\alpha$ & IL-10 \\
\hline IL-2 & IL-13 \\
\hline IL-6 & TNF soluble receptors \\
\hline IL-8 & IL-1 soluble receptors \\
\hline IL-15 & Transforming growth factor $\beta$ \\
\hline IL-18 & \\
\hline Epidermal growth factor (EGF) & \\
\hline Fibroblast growth factor & \\
\hline Nerve growth factor (NGF) & \\
\hline Brain-derived neurotrophic factor (BDNF) & \\
\hline Neutrophins 3 and 4 & \\
\hline Glial derived neurotrophic factor & \\
\hline IFN (alpha and beta) & \\
\hline $\begin{array}{c}\text { Granulocyte-macrophage colony } \\
\text { stimulating factor GM-CSF) }\end{array}$ & \\
\hline
\end{tabular}

IL-1 and TNF- $\alpha$ have been shown to be somnogenic in every species thus far tested (e.g. humans, mice, rats, cats, monkeys, and rabbits) and are effective whether given directly into the brain or after intraperitoneal or intravenous injections. The effect of cytokine administration is dosedependent. For instance, although IL-1 and TNF- $\alpha$ appear to induce physiological sleep, high doses of IL-1 rather inhibit than promote sleep. Rabbits given IL-1 at dark onset sleep about 3 extra $\mathrm{h}$ during the first $12 \mathrm{~h}$ after the injection but normal sleep patterns were maintained [2].

Administration of TNF- $\alpha$ or IL-1 $\beta$ increases the amplitude of slow wave EEG, while that of IL-10 and IL-4, inhibits NREM. Interestingly, each of these cytokines influences the effect the other has on sleep. Pre-treatment with a fragment of the receptor for IL-1 $\beta$ (type 1 IL-1r, IL$1 \mathrm{r} 1$ ) attenuates TNF- induced NREM enhancement, and TNF antagonists inhibit IL-1 $\beta$-induced increases in NREM duration [2].

TNF and IL- $1 \beta$ both stimulate the transcriptional activity of NF- $\kappa B$ and enhance sleep. Factors that inhibit NF- $\kappa B$ activation, such as IL-4, IL-10 and inhibitor of NF- $\kappa B$ inhibit sleep. NF- $\kappa B$ itself promotes the production on TNF and IL$1 \beta$, forming a positive -feedback loop, possibly to promote the homeostatic drive for sleep. This is supported by the finding that sleep deprivation causes increased levels of NF$\kappa \mathrm{B}$ in the CNS [97] (Fig. 1).
As already mentioned, IL-1 levels in the brain correlated with sleep propensity, being highest at sleep onset, and together with other proinflammatory cytokines were able to regulate physiologic body temperature and appetite [98]. Other cytokines that are reported to increase NREM sleep include IL-2, IL6, IL-8, IL-15 and IL-18.

Cytokines that disrupt NREM sleep (stages 3 and 4) have been less examined, but the best established are IL-4 and IL10. These cytokines function by inhibiting the production of IL- 1 and TNF- $\alpha$, probably via inhibition of NF $\kappa$ B activation [2]. Intracerebral injections in rabbits of a cell permeable inhibitor peptide of NF $\kappa \mathrm{B}$ inhibit both spontaneous and IL$1 \beta$ induced sleep [99]. Also intracerebral injections of TNF- $\alpha$ and IL-1 inhibitors in rabbits significantly reduced spontaneous NREM sleep, whereas pretreatment with inhibitors of these cytokines significantly attenuated sleep rebound after sleep deprivation. IL-4 has been shown in animals to reduce slow wave sleep [2]. IL-10, produced by lymphocytes and monocytes, inhibits the production of TNF$\alpha$, and inhibits slow wave sleep in rabbits. In contrast, IL-10 knockout mice have increased slow wave sleep [100]. Other cytokines reported to have sleep inhibiting effects are IL-13 and transforming growth factor (TGF)- $\beta$ (Table 4).

\section{INFLAMMATION AFFECTS BOTH SLEEP AND CIRCADIAN RHYTHMICITY}

During acute or chronic infection and inflammation complex changes in a variety of physiological systems occur. In addition to changes in temperature or the induction of fever, behavioral changes like somnolence, tiredness, flu-like symptoms and impaired concentration are common [101103]. Knowledge about the underlying mechanisms has accumulated; one of the first important findings in this respect was the observation that the HPA is stimulated after the peripheral administration of IL-1 [104]. After this basic finding in psychoneuroimmunology research further studies focused on the inflammatory cytokines such as IL-1 as major components in the interaction of peripheral immune function and CNS [33]. In human research mainly cytokines of the ILs, IFNs or TNFs families have been investigated. Inflammatory stimuli can induce CNS stress response both through central mechanisms as well as through afferent peripheral neural signaling [32]. The latter was shown mainly for cytokines from the peritoneum that can cause early rapid activation of the nucleus tractus solitarius in the brainstem via the vagus nerve.

Experimental evidence suggests that symptomatology after antigen administration, like anorexia and depressed activity, is a part of a defense response to antigenic challenge and is mediated by the neural effects of cytokines. These changes are known generally as "sickness behavior", that is, the "nonspecific" symptoms (anorexia, depressed activity, loss of interest in usual activities, disappearance of body care activities) that accompany the response to infection [102, 103]. These symptoms of infection include fever and profound psychological and behavioral changes in circadian structure. Sick individuals experience weakness, malaise, listlessness and inability to concentrate. They consistently show evidence of decreased amplitude of circadian rhythmicity, like superficial sleep at night and hypersomnia, 
loss of interest and depressed activity during the day [102, 103].

Numerous studies showed that the therapeutic administration of cytokines for the treatment of hepatitis, cancer, multiple sclerosis or rheumathoid arthritis induces depressive symptomatology which widely overlaps with the syndrome of "sickness behavior". In healthy human beings most experiments have not injected cytokines themselves but administered bacterial endotoxin. A highly purified preparation derived from Salmonella abortus equi was used, an endotoxin stripped of protein, prepared specifically for use in humans. Very low amounts of bacterial endotoxin $(0.2$ $\mathrm{ng} / \mathrm{kg}$ ) administered to healthy volunteers at 2300 hours induced neither neuroendocrine activation nor an increase in body temperature, but an increase in TNF- $\alpha$ and IL-6 levels to about $200 \%$ of baseline [105]. The administration of intermediate dosages of $0.4 \mathrm{ng} / \mathrm{kg}$ body weight in the evening or of $0.8 \mathrm{ng} / \mathrm{kg}$ in the morning were followed by more robust increases in cytokine plasma levels and by a slight, but significant activation of the HPA-system in parallel to increases of body temperature of about 0.5-1.0 C. Finally, injections of $0.8 \mathrm{ng} / \mathrm{kg}$ body weight in the evening led to even higher fever and increased the levels of cytokines and hormones even stronger [105]. Following the different stimulation conditions, sleep is changed. NREM sleep was influenced by the acute phase response in a bimodal manner: when slight increases in inflammatory cytokines occurred without concomitant neuroendocrine activation, NREM sleep was slightly increased. When immune parameters were more strongly increased and fever was induced, sleep continuity and NREM sleep amount were reduced. REM sleep changes are less complex, the amount of REM sleep suppression is directly related to the induction of temperature increased [106].

In face of prominent immunological changes, other mechanisms like the activation in HPA-system can lead to a disturbance in sleep continuity and a reduction of NREM sleep $[32,89]$. This view is also supported by the fact that in humans experimental enhancement of the circulating amounts of cytokine antagonists (IL-1 $\mathrm{r}$ antagonist and soluble TNF r) transiently suppressed NREM sleep [107]. Additionally, there is some evidence that psychotropic drugs which tend to slightly increase circulating TNF- $\alpha$ levels are sedating or increase NREM sleep amount [108].

Medications that block the effects of inflammatory cytokines appear to improve sleep and fatigue during the day. In rheumatoid arthritis patients who showed a markedly poor sleep, a single dose administration of infliximab, a TNF- $\alpha$ antagonist, produced rapid, marked improvements in objective measurement of sleep efficiency and sleep latency, before any improvement in clinical markers like joint pain and swelling [109]. Similarly, in obese sleep apnea patients, administration of etanercept, another TNF- $\alpha$ antagonist medication, produced decreases in self-reported lethargy and less sleepiness, measured via increased sleep onset times in response to the multiple sleep latency test [110]. These studies suggest that blockage of inflammatory cytokines lead to an improved sleep.

Results in hamsters indicate that LPS treatment induces changes in the phase of locomotor activity rhythms in a manner similar to light-induced phase delays [111]. The phase-shifting response to LPS was reduced when the activation of NF- $\kappa \mathrm{B}$, that reportedly plays a role in the photic input of the circadian system [61], was prevented. LPS treatment stimulates the dorsal area of the $\mathrm{SCN}$ as assessed by c-Fos activation [111].

Data from our laboratory indicate that melatonin, administered in the drinking water, has the capacity to counteract the effect of LPS on body temperature in hamsters, when injected at "Zeitgeber" time (ZT) 0 (ZT12 defined as the time of light off) [112]. Evidence that melatonin improves survival from endotoxin shock has also been published [113, 114].

Therefore, one possible mechanism through which infection-related changes in circadian rhythms can occur is by modifying directly the activity of cells in the SCN. Former studies indicating the presence of cytokine receptors, e.g. IFN- $\gamma$ receptors, in SCN [115] have now been confirmed and extended (for ref. see [60]). Expression of SCN IFN- $\gamma$ receptors followed a 24-h rhythm, coinciding with the expression of Janus kinase 1 and 2 as well as the signal transducer and activator of transcription factor 1, the main intracellular signaling pathway for IFN- $\gamma$. In an ontogeny study, SCN IFN- $\gamma$ receptors were found to reach their adult pattern between postnatal day 11 and 20 , at a time when capacity for photic entrainment of the pacemaker became established [116]. Indeed, high doses of an IFN- $\gamma$ / TNF- $\alpha$ cocktail disrupt electrical activity of SCN neurons [117, 118].

The capacity of intracerebroventricular administration of IFN- $\gamma$ to modify $24-\mathrm{h}$ wheel running activity was assessed by us in golden hamsters [119]. Animals received IFN- $\gamma$ or saline at $\mathrm{ZT} 6$ or $\mathrm{ZT} 18$. Intracerebroventricular administration of IFN- $\gamma$ at ZT 6 produced a significant phase advance in acrophase of rhythm, an effect not seen with injection at ZT 18. IFN- $\gamma$ depressed mesor value of rhythm significantly; the effect was seen both with ZT 6 and ZT 18 injections [119]. IFN- $\gamma$ was very effective to disrupt circadian rhythmicity of pituitary hormone release [120]. The results supported the view that the circadian sequels arising during the immune reaction can rely partly on central effects of IFN- $\gamma$ [119].

A disruptive effect of systemic administration of IFN- $\alpha$ on the circadian rhythm of locomotor activity, body temperature and clock-gene mRNA expression in SCN has been documented in mice [121]. Moreover, LPS incubation modified the circadian arginine-vasopressin release from SCN cultures [122]. Motzkus et al. [56] demonstrated that IL-6 induced murine Per1 expression in SCN cell cultures.

In a study on day/night variations of SCN transcripts encoding cytokine receptors and suppressors of cytokine signaling were correlated in groups of mice of different ages with Fos induction elicited by intracerebroventricular injections of TNF- $\alpha$ and IFN- $\gamma$ [123]. Cytokine-elicited Fos induction was high at early night, when suppressors of cytokine signaling levels were low. Such Fos induction was significantly reduced in the older SCN at early night, and paralleled by reduced expression of IFN- $\gamma$ receptor transcripts as compared to the younger SCN.

In recent years we examined the circadian disruption of hormone release and immune-related mechanisms in several 
animal models in which circulating cytokines increased, including rat adjuvant arthritis, alcoholism, calorie restriction, social isolation in rats and rabbits, and the aging process. Basic rationale for the experimental approach used was that most published studies dealing with hormone or immune changes in the above mentioned situations were performed at single time-points in the 24-h span, an important drawback in view of the circadian nature of hormone release and immune function and on the fact that most manipulations employed disrupt circadian rhythmicity. The results obtained are summarized elsewhere [124].

\section{THERE ARE SIMILARITIES BETWEEN EXTREME SLEEP DEPRIVATION AND MULTIPLE ORGAN DYSFUNCTION SYNDROME (MODS)}

Total sleep deprivation in rats brings about the appearance of a complex clinical picture that leads to death between 11 and 32 days later [125]. Such a situation is readily reversed if the animals are allowed to sleep again. Sleep-deprived animals are killed by a poorly defined set of causes, including sepsis and thermoregulatory and metabolic imbalance. The animal looks weak with ulcerative lesions occurring in skin including hyperkeratosis and loss of hair. Food intake increased by $80-100 \%$ over baseline but despite the increased food intake, the body weight decreased by $20 \%$. This decrease is not explained by dehydration or malabsorption. The metabolic energy cost increases by about $100 \%$ before death. Body temperature increases during the first phase of the survival period followed by hypothermia. There is an increase in plasma levels of norepinephrine with an augmented T3/T4 ratio [125].

This picture strikingly resembles MODS seen in intensive care medicine [126]. MODS leads to emaciation of the patient and ends in death within a short period ("autocannibalism"). Gastric ulcers and hemorrhagic necrosis are found in many organs with lesions unrelated to the pathogenic agent. In the first phase of MODS, a reduced oxygen consumption, vasoconstriction and hypothermia $(<36 \mathrm{C})$ are found. A hyperthermic phase then ensues. Energy expenditure increases $40-60 \%$ or more with a significant weight loss during the second phase of MODS. This hypermetabolic and hypercatabolic phase, including augmented glycolysis, gluconeogenesis and muscle proteolysis, elapses for 7 to 10 days. A documented hypersecretion of $\mathrm{ADH}$, prolactin, ACTH and GH occur, followed by increased levels of cortisol, glucagon, catecholamines and insulin. If this phase is not controlled, hypermetabolism grows and perpetuates with increased oxygen consumption, tachycardia, thyroid hormoneinduced thermogenesis and death.

MODS occurs after surgical or traumatic injury and is associated with severe sepsis, septic shock, hemorrhagic pancreatitis, and the simultaneous or sequential involvement of different organ systems [127-130]. After an initial phase (that generally recovers with treatment) there is a latency period which is interrupted by the rapid onset of sepsis at 7-14 days of injury and a progressive involvement of organs and systems. An impending respiratory failure often characterized MODS, and this is followed by the failure of other organs: kidney, liver, cardiovascular system, coagulation, CNS, etc. The lung is affected in almost $100 \%$ of cases being followed by kidney's involvement [129, 130].
Although sepsis is considered a major cause of the high mortality rate in MODS it is not the only factor. Tissue necrosis and inflammatory reaction are widespread throughout the organism. The sepsis is difficult to identify by a positive blood culture (presently only in $50 \%$ of patients) but post mortem examination in MODS indicates always sepsis in organs and tissues.

The generalized failure of organs, both anatomically and functionally, suggests a common mechanism of cellular injury in MODS and experimental sleep deprivation. A cascade of mechanisms activated in MODS include complement activation, activation of Hageman factor (factor XII) and the release of various mediators (TNF- $\alpha$, IL's, platelet activator factor, histamine, free radicals, leukotrienes, PGs, etc.). All this leads to inflammation, which is initially adaptive, but when it exceeds a certain level, is uncontrolled. Overactivation of effector cells (neutrophils, macrophages, lymphocytes) damages the vascular endothelium. Therefore, there is a clear implication of the immune system in MODS [127-130]. Therefore while the consequences of MODS and sleep deprivation are not identical, their similarity is striking [126].

\section{CONCLUSIONS}

From a physiological perspective the sleep-wake cycle can be viewed as a sequence of three different physiological states, wakefulness, NREM and REM. These three states are defined by a particular programming of neuroendocrine, immune and autonomic responses. As far as the immune system, the sympathetic predominance occurring in wakefulness is manifested in facilitating Th2 responses at the expense of Th1, whereas in NREM sleep, the parasympathetic dominance results in the reverse situation. There are no reliable data on what happens with the immune response during REM sleep.

In turn, as a consequence of the immune response, there are verifiable significant changes in neuronal activity. Different groups of hypothalamic neurons respond to humoral signals (cytokines) produced by immunocompetent cells and are themselves capable of producing cytokines. The central or peripheral administration of IL-1 or TNF- $\alpha$ increases NREM and suppresses REM sleep. Mice with knockout of IL-1 receptor type I or p55 TNF- $\alpha$ genes sleep less. A prolonged wakefulness increases mRNA for IL-1 and TNF- $\alpha$ in brain and there is a direct relationship between the increase of mRNA levels for IL- 1 and TNF- $\alpha$ in the anterior hypothalamus and the triggering of NREM sleep. Other cytokines the have been shown to have activity on sleep are: IFN- $\gamma$, IL-2, IL-4, IL-6, IL-10, IL-13, IL-15, IL-18, GM$\mathrm{CSF}, \mathrm{FGF}, \mathrm{NGF}, \mathrm{BDNF}, \mathrm{GDNF}$ and TGF- $\beta$. It is possible that through visceral chemoreceptors present in tissue and the immune signals produced by immunocompetent cells (cytokines), sensory afferent information is provided during the course of the immune response that affects the mechanism of sleep.

\section{ACKNOWLEDGEMENTS}

Studies in authors' laboratories were supported by grants from Ministerio de Educación y Ciencia, Spain and Agencia Nacional de Promoción Científica y Tecnológica, Argentina 
(PICT 2007-01045). DPC is a Research Career Awardee from the Argentine Research Council (CONICET).

\section{CONFLICT OF INTEREST}

Declared none.

\section{REFERENCES}

[1] Krueger JM, Karnovsky ML, Martin SA, et al. Peptidoglycans as promoters of slow-wave sleep. II. Somnogenic and pyrogenic activities of some naturally occurring muramyl peptides; correlations with mass spectrometric structure determination. J Biol Chem 1984; 259: 12659-62.

[2] Krueger JM. The role of cytokines in sleep regulation. Curr Pharm Des 2008; 14: 3408-16.

[3] Psndi-Perumal SR, Cardinali DP, Chrousos GP. Neuroimmunology of Sleep. New York, Springer Science+Business Media, LLC, 2007.

[4] Rechtschaffen A, Kales A. A Manual of Standardized Terminology, Techniques, and Scoring System for Sleep Stages of Human Subjects. Bethesda, MD, US Department of Health, Education, and Welfare Public Health Service- NIH/NIND, 1968.

[5] Beersma DGM. Models of human sleep regulation. Sleep Med Rev 1998;2:31-43.

[6] Pace-Schott EF, Hobson JA. The neurobiology of sleep: genetics, cellular physiology and subcortical networks. Nature Neurosci Rev 2002; 3: 591-605.

[7] Parmeggiani PL, Velluti R. The Physiological Nature of Sleep. London, Imperial College Press, 2005.

[8] Dijk DJ. Regulation and functional correlates of slow wave sleep. J Clin Sleep Med 2009; 5: S6-15.

[9] Gangwisch JE. Epidemiological evidence for the links between sleep, circadian rhythms and metabolism. Obes Rev 2009; 10(Suppl 2): 37-45

[10] Gimble JM, Bray MS, Young A. Circadian biology and sleep: missing links in obesity and metabolism? Obes Rev 2009; 10(Suppl 2): $1-5$.

[11] Gorgulu Y, Caliyurt O. Rapid antidepressant effects of sleep deprivation therapy correlates with serum BDNF changes in major depression. Brain Res Bull 2009; 80: 158-62.

[12] Lee KS, Alvarenga TA, Guindalini C, et al. Validation of commonly used reference genes for sleep-related gene expression studies. BMC Mol Biol 2009; 10: 45

[13] Faraguna U, Vyazovskiy VV, Nelson AB, et al. A causal role for brain-derived neurotrophic factor in the homeostatic regulation of sleep. J Neurosci 2008; 28: 4088-95.

[14] Hobson JA. REM sleep and dreaming: towards a theory of protoconsciousness. Nat Rev Neurosci 2009; 10: 803-13.

[15] Reddy AB, Wong GK, O'neill J, et al. Circadian clocks: Neural and peripheral pacemakers that impact upon the cell division cycle. Mutat Res 2005; 574: 76-91.

[16] Morin LP, Allen CN: The circadian visual system, 2005. Brain Res Brain Res Rev 2006; 51: 1-60.

[17] Bonnefont X. Circadian timekeeping and multiple timescale neuroendocrine rhythms. J Neuroendocrinol 2010; 22(3): 209-16.

[18] Okamura $\mathrm{H}$. Integration of mammalian circadian clock signals: from molecule to behavior. J Endocrinol 2003; 177: 3-6.

[19] Collins B, Blau J. Keeping time without a clock. Neuron 2006;50:348-50.

[20] Lakin-Thomas PL. Transcriptional feedback oscillators: maybe, maybe not.. J Biol Rhythms 2006; 21: 83-92.

[21] Borbely AA. A two process model of sleep regulation. Hum Neurobiol 1982; 1: 195-204.

[22] Dijk DJ, Duffy JF. Circadian regulation of human sleep and agerelated changes in its timing, consolidation and EEG characteristics. Ann Med 1999; 31: 130-40.

[23] Scheer FA, Wright KP, Jr., Kronauer RE, et al. Plasticity of the intrinsic period of the human circadian timing system. PLoS ONE 2007; 2: e721

[24] Pandi-Perumal SR, Moscovitch A, Srinivasan V, et al. Bidirectional communication between sleep and circadian rhythms and its implications for depression: lessons from agomelatine. Prog Neurobiol 2009; 88: 264-71
[25] Sack RL, Lewy AJ, Blood ML, et al. Circadian rhythm abnormalities in totally blind people: incidence and clinical significance. J Clin Endocrinol Metab 1992; 75: 127-34.

[26] Dijk DJ, Shanahan TL, Duffy JF, et al. Variation of electroencephalographic activity during non-rapid eye movement and rapid eye movement sleep with phase of circadian melatonin rhythm in humans. J Physiol 1997; 505( Pt 3): 851-8.

[27] Pandi-Perumal SR, Trakht I, Srinivasan V, et al. Physiological effects of melatonin: role of melatonin receptors and signal transduction pathways. Prog Neurobiol 2008; 185: 335-53.

[28] Lewy AJ, Emens J, Jackman A, et al. Circadian uses of melatonin in humans. Chronobiol Int 2006; 23: 403-12.

[29] Lavie P. Sleep-wake as a biological rhythm. Annu Rev Psychol 2001; 52: 277-303.

[30] Dimitrov S, Lange T, Tieken S, et al. Sleep associated regulation of T helper 1/T helper 2 cytokine balance in humans. Brain Behav Immun 2004; 18: 341-8.

[31] Berger J. A two-clock model of circadian timing in the immune system of mammals. Pathol Biol (Paris) 2008; 56: 286-91.

[32] Chrousos GP: Stress and disorders of the stress system. Nat Rev Endocrinol 2009; 5: 374-81.

[33] Opp MR. Sleep and psychoneuroimmunology. Immunol Allergy Clin North Am 2009; 29: 295-307.

[34] Kidd P. Th1/Th2 balance: the hypothesis, its limitations, and implications for health and disease. Altern Med Rev 2003; 8: 223 46.

[35] Corthay A. How do regulatory T cells work? Scand J Immunol 2009; 70: 326-36.

[36] Williams HC, Grindlay DJ. What's new in atopic eczema? An analysis of systematic reviews published in 2007 and 2008. Part 1. Definitions, causes and consequences of eczema. Clin Exp Dermatol 2010; 35: 12-5.

[37] Miller GE, Cohen S, Pressman S, et al. Psychological stress and antibody response to influenza vaccination: when is the critical period for stress, and how does it get inside the body? Psychosom Med 2004; 66: 215-23.

[38] Dopp JM, Wiegert NA, Moran JJ, et al. Humoral immune responses to influenza vaccination in patients with obstructive sleep apnea. Pharmacotherapy 2007; 27: 1483-9.

[39] Rector DM, Schei JL, Van Dongen HP, et al. Physiologica markers of local sleep. Eur J Neurosci 2009; 29: 1771-8.

[40] Bollinger T, Bollinger A, Oster H, et al. Sleep, immunity, and circadian clocks: a mechanistic model. Gerontology 2010; 56(6): 574-80..

[41] Petrovsky N, Harrison LC. The chronobiology of human cytokine production. Int Rev Immunol 1998; 16: 635-49.

[42] Buijs RM, Scheer FA, Kreier F, et al. Chapter 20: Organization of circadian functions: interaction with the body. Prog Brain Res 2006; 153: 341-60

[43] Cutolo M, Sulli A, Pizzorni C, et al. Circadian rhythms: glucocorticoids and arthritis. Ann N Y Acad Sci 2006; 1069: 289 99.

[44] Hayashi M, Shimba S, Tezuka M. Characterization of the molecular clock in mouse peritoneal macrophages. Biol Pharm Bull 2007; 30: 621-6.

[45] Murphy BA, Vick MM, Sessions DR, et al. Acute systemic inflammation transiently synchronizes clock gene expression in equine peripheral blood. Brain Behav Immun 2007; 21: 467-76.

[46] Zhu Y, Leaderer D, Guss C, et al. Ala394Thr polymorphism in the clock gene NPAS2: a circadian modifier for the risk of nonHodgkin's lymphoma. Int J Cancer 2007; 120: 432-5.

[47] Liu J, Mankani G, Shi X, et al. The circadian clock Period 2 gene regulates gamma interferon production of NK cells in host response to lipopolysaccharide-induced endotoxic shock. Infect Immun 2006; 74: 4750-6.

[48] Arjona A, Sarkar DK. Evidence supporting a circadian control of natural killer cell function. Brain Behav Immun 2006; 20: 469-76.

[49] Boivin DB, James FO, Wu A, et al. Circadian clock genes oscillate in human peripheral blood mononuclear cells. Blood 2003; 102: 4143-5.

[50] Kusanagi H, Mishima K, Satoh K, et al. Similar profiles in human period1 gene expression in peripheral mononuclear and polymorphonuclear cells. Neurosci Lett 2004; 365: 124-7.

[51] Arjona A, Sarkar DK. Circadian oscillations of clock genes, cytolytic factors, and cytokines in rat NK cells. J Immunol 2005 174: 7618-24. 
[52] Kobayashi H, Oishi K, Hanai S, et al. Effect of feeding on peripheral circadian rhythms and behaviour in mammals. Genes to Cells 2004; 9: 857-64.

[53] Filipski E, King VM, Etienne MC, et al. Persistent twenty-four hour changes in liver and bone marrow despite suprachiasmatic nuclei ablation in mice. Am J Physiol Regul Integr Comp Physiol 2004; 287: R844-R851

[54] Wu MW, Li XM, Xian LJ, et al. Effects of meal timing on tumor progression in mice. Life Sci 2004; 75: 1181-93.

[55] Schibler U, Ripperger J, Brown SA. Peripheral circadian oscillators in mammals: time and food. J Biol Rhythms 2003; 18: 250-60.

[56] Motzkus D, Albrecht U, Maronde E. The human PER1 gene is inducible by interleukin-6. J Mol Neurosci 2002; 18: 105-9.

[57] Cardinali DP, Cutrera R, Castrillon P, et al. Diurnal rhythms in ornithine decarboxylase activity and norepinephrine and acetylcholine synthesis and acetylcholine synthesis of rat submaxillary lymph nodes: effect of pinealectomy, superior cervical ganglionectomy and melatonin replacement. Neuroimmunomodulation 1996; 3: 102-11.

[58] Cardinali DP, Esquifino AI. Neuroimmunoendocrinology of the cervical autonomic nervous system. Biomed Rev 1998; 9: 47-59.

[59] Cardinali DP, Garcia AP, Cano P, et al. Melatonin role in experimental arthritis. Curr Drug Targets Immune Endocr Metabol Disord 2004; 4: 1-10.

[60] Coogan AN, Wyse CA. Neuroimmunology of the circadian clock. Brain Res 2008;1232: 104-12.

[61] Marpegan L, Bekinschtein TA, Freudenthal R, et al. Participation of transcription factors from the Rel/NF-[kappa]B family in the circadian system in hamsters. Neurosci Lett 2004; 358: 9-12.

[62] Selgas L, Pazo D, Arce A, et al. Circadian rhythms in adenohypophysial hormone levels and hypothalamic monoamine turnover in mycobacterial adjuvant-injected rats. Biol Signals Recept 1998; 7: 15-24.

[63] Esquifino AI, Selgas L, Vara E, et al. Twenty-four rhythms of hypothalamic corticotropin-releasing hormone, thyrotropinreleasing hormone, growth hormone-releasing hormone and somatostatin in rats injected with Freund's adjuvant. Biol Signals Recept 1999; 8: 178-90.

[64] Pandi-Perumal SR, Srinivasan V, Maestroni GJM, et al. Melatonin: Nature's most versatile biological signal? FEBS J 2006; 273 (13): 2813-38.

[65] Garcia-Maurino S, Pozo D, Calvo JR, et al. Correlation between nuclear melatonin receptor expression and enhanced cytokine production in human lymphocytic and monocytic cell lines. J Pineal Res 2000; 29: 129-37.

[66] Carrillo-Vico A, Reiter RJ, Lardone PJ, et al. The modulatory role of melatonin on immune responsiveness. Curr Opin Investig Drugs 2006; 7: 423-31.

[67] Drazen DL, Nelson RJ. Melatonin receptor subtype $\mathrm{MT}_{2}$ (Mel 1b) and not $\mathrm{mt}_{1}$ (Mel 1a) is associated with melatonin-induced enhancement of cell-mediated and humoral immunity. Neuroendocrinology 2001; 74: 178-84.

[68] Currier NL, Sun LZ, Miller SC. Exogenous melatonin: quantitative enhancement in vivo of cells mediating non-specific immunity. J Neuroimmunol 2000; 104: 101-8.

[69] Kaur C, Ling EA. Effects of melatonin on macrophages/microglia in postnatal rat brain. J Pineal Res 1999; 26: 158-68.

[70] Markus RP, Ferreira ZS, Fernandes PA, et al. The immune-pineal axis: a shuttle between endocrine and paracrine melatonin sources. Neuroimmunomodulation 2007; 14: 126-33.

[71] Srinivasan V, Spence DW, Moscovitch A, et al. Malaria: therapeutic implications of melatonin. J Pineal Res 2010; 48: 1-8.

[72] Carillo-Vico A, Reiter RJ, Lardone PJ, et al. The modulatory role of melatonin on immune responsiveness. Curr Opin Investig Drugs 2006; 7: 423-31.

[73] Fildes JE, Yonan N, Keevil BG. Melatonin--a pleiotropic molecule involved in pathophysiological processes following organ transplantation. Immunology 2009; 127: 443-9.

[74] Conti A, Conconi S, Hertens E, et al. Evidence for melatonin synthesis in mouse and human bone marrow cells. J Pineal Res 2000; 28: 193-202.

[75] Castrillón P, Cardinali DP, Pazo D, et al. Effect of superior cervical ganglionectomy on 24-h variations in hormone secretion from anterior hypophysis and in hypothalamic monoamine turnover, during the preclinical phase of Freund's adjuvant arthritis in rats. J Neuroendocrinol 2001; 13: 288-95.
[76] Nunnari G, Nigro L, Palermo F, et al. Reduction of serum melatonin levels in HIV-1-infected individuals' parallel disease progression: correlation with serum interleukin-12 levels. Infection 2003; 31: 379-82.

[77] Yu Q, Miller SC, Osmond DG. Melatonin inhibits apoptosis during early B-cell development in mouse bone marrow. J Pineal Res 2000; 29: 86-93.

[78] Irwin M, Clark C, Kennedy B, et al. Nocturnal catecholamines and immune function in insomniacs, depressed patients, and control subjects. Brain Behav Immun 2003; 17: 365-72.

[79] Okun ML, Giese S, Lin L, et al. Exploring the cytokine and endocrine involvement in narcolepsy. Brain Behav Immun 2004; 18: 326-32.

[80] Vgontzas AN, Zoumakis E, Bixler EO, et al. Adverse effects of modest sleep restriction on sleepiness, performance, and inflammatory cytokines. J Clin Endocrinol Metab 2004; 89: 211926.

[81] Savard J, Laroche L, Simard S, et al. Chronic insomnia and immune functioning. Psychosom Med 2003; 65: 211-21.

[82] Dinges DF, Douglas SD, Hamarman S, et al. Sleep deprivation and human immune function. Adv Neuroimmunol 1995; 5: 97-110.

[83] Heiser P, Dickhaus B, Schreiber W, et al. White blood cells and cortisol after sleep deprivation and recovery sleep in humans. Eur Arch Psychiatry Clin Neurosci 2000; 250: 16-23.

[84] Redwine L, Hauger RL, Gillin JC, et al. Effects of sleep and sleep deprivation on interleukin-6, growth hormone, cortisol, and melatonin levels in humans. J Clin Endocrinol Metab 2000; 85: 3597-603.

[85] Vgontzas AN, Bixler EO, Lin HM, et al. IL-6 and its circadian secretion in humans. Neuroimmunomodulation 2005; 12: 131-40.

[86] Marshall L, Born J. Brain-immune interactions in sleep. Int Rev Neurobiol 2002; 52: 93-131.

[87] Born J, Lange T, Hansen K, et al. Effects of sleep and circadian rhythm on human circulating immune cells. J Immunol 1997; 158: 4454-64.

[88] Moldofsky H, Dickstein JB. Sleep and cytokine-immune functions in medical, psychiatric and primary sleep disorders. Sleep Med Rev 1999; 3: 325-37.

[89] McEwen BS. Sleep deprivation as a neurobiologic and physiologic stressor: allostasis and allostatic load. Metabolism 2006; 55: S20S3

[90] Leproult R, Copinschi G, Buxton O, et al. Sleep loss results in an elevation of cortisol levels the next evening. Sleep 1997; 20: 86570 .

[91] Meerlo P, Sgoifo A, Suchecki D. Restricted and disrupted sleep: effects on autonomic function, neuroendocrine stress systems and stress responsivity. Sleep Med Rev 2008; 12: 197-210.

[92] $\mathrm{Hu}$ J, Chen Z, Gorczynski CP, et al. Sleep-deprived mice show altered cytokine production manifest by perturbations in serum IL1ra, TNFa, and IL-6 levels. Brain Behav Immun 2003; 17: 498504.

[93] Besedovsky HO, Del Rey A. Immune-neuro-endocrine interactions: facts and hypotheses. Endocr Rev 1996; 17: 64-102.

[94] Ziebell JM, Morganti-Kossmann MC. Involvement of pro- and anti-inflammatory cytokines and chemokines in the pathophysiology of traumatic brain injury. Neurotherapeutics 2010; 7: 22-30

[95] Wu YW, Croen LA, Torres AR, et al. Interleukin-6 genotype and risk for cerebral palsy in term and near-term infants. Ann Neurol 2009; 66: 663-70.

[96] Mills PJ, Dimsdale JE. Sleep apnea: a model for studying cytokines, sleep, and sleep disruption. Brain Behav Immun 2004; 18: 298-303.

[97] Bryant PA, Trinder J, Curtis N. Sick and tired: Does sleep have a vital role in the immune system? Nat Rev Immunol 2004; 4: 457 67.

[98] Szelenyi J. Cytokines and the central nervous system. Brain Res Bull 2001; 54: 329-38

[99] Kubota T, Fang J, Kushikata T, et al. Interleukin-13 and transforming growth factor-betal inhibit spontaneous sleep in rabbits. Am J Physiol Regul Integr Comp Physiol 2000; 279: R786R792

[100] Toth LA, Opp MR. Cytokine- and microbially induced sleep responses of interleukin-10 deficient mice. Am J Physiol Regul Integr Comp Physiol 2001; 280: R1806-R14 
[101] Marques AH, Silverman MN, Sternberg EM. Glucocorticoid dysregulations and their clinical correlates. From receptors to therapeutics. Ann N Y Acad Sci 2009; 1179: 1-18.

[102] Pecchi E, Dallaporta M, Jean A, et al. Prostaglandins and sickness behavior: old story, new insights. Physiol Behav 2009; 97: 279-92.

[103] Myers JS. Proinflammatory cytokines and sickness behavior: implications for depression and cancer-related symptoms. Oncol Nurs Forum 2008; 35: 802-7.

[104] Besedovsky H, del Rey A, Sorkin E, et al. Immunoregulatory feedback between interleukin-1 and glucocorticoid hormones. Science 1986; 233: 652-4.

[105] Mullington J, Korth C, Hermann DM, et al. Dose-dependent effects of endotoxin on human sleep. Am J Physiol Regul Integr Comp Physiol 2000; 278: R947-R55

[106] Schuld A, Haack M, Hinze-Selch D, et al. [Experimental studies on the interaction between sleep and the immune system in humans]. Psychother Psychosom Med Psychol 2005; 55: 29-35.

[107] Schuld A, Mullington J, Hermann D, et al. Effects of granulocyte colony-stimulating factor on night sleep in humans. Am J Physiol 1999; 276: R1149-R55

[108] Pollmacher T, Haack M, Schuld A, et al. Effects of antipsychotic drugs on cytokine networks. J Psychiatr Res 2000; 34: 369-82.

[109] Zamarron C, Maceiras F, Mera A, et al. Effect of the first infliximab infusion on sleep and alertness in patients with active rheumatoid arthritis. Ann Rheum Dis 2004; 63: 88-90.

[110] Vgontzas AN, Zoumakis E, Lin HM, et al. Marked decrease in sleepiness in patients with sleep apnea by etanercept, a tumor necrosis factor-alpha antagonist. J Clin Endocrinol Metab 2004; 89: 4409-13.

[111] Marpegan L, Bekinschtein TA, Costas MA, et al. Circadian responses to endotoxin treatment in mice. J Neuroimmunol 2005; 160: 102-9.

[112] Bruno VA, Scacchi P, Pérez Lloret S, et al. Melatonin treatment counteracts the hyperthermic effect of lipopolysaccharide injection in the syrian hamster. Neurosci Lett 2005; 389: 169-72.

[113] Maestroni GJ. Melatonin as a therapeutic agent in experimental endotoxic shock. J Pineal Res 1996; 20: 84-9.

[114] Crespo E, Macias M, Pozo D, et al. Melatonin inhibits expression of the inducible NO synthase II in liver and lung and prevents endotoxemia in lipopolysaccharide-induced multiple organ dysfunction syndrome in rats. FASEB J 1999; 13: 1537-46.

[115] Lundkvist GB, Robertson B, Mhlanga JD, et al. Expression of an oscillating interferon-gamma receptor in the suprachiasmatic nuclei. Neuroreport 1998; 9: 1059-63.
[116] Lundkvist GB, Andersson A, Robertson B, et al. Light-dependent regulation and postnatal development of the interferon-gamma receptor in the rat suprachiasmatic nuclei. Brain Res 1999; 849: 231-4.

[117] Lundkvist GB, Hill RH, Kristensson K. Disruption of circadian rhythms in synaptic activity of the suprachiasmatic nuclei by african trypanosomes and cytokines. Neurobiol Dis 2002;11: 20-7.

[118] Lundkvist GB, Kristensson K, Hill RH. The suprachiasmatic nucleus exhibits diurnal variations in spontaneous excitatory postsynaptic activity. J Biol Rhythms 2002; 17: 40-51.

[119] Boggio V, Castrillon P, Pérez Lloret S, et al. Cerebroventricular administration of interferon-gamma modifies locomotor activity in the golden hamster. NeuroSignals 2003; 12: 89-94.

[120] Cano P, Cardinali DP, Jimenez V, et al. Effect of interferon-gamma treatment on 24-hour variations in plasma $\mathrm{ACTH}$, growth hormone, prolactin, luteinizing hormone and follicle-stimulating hormone of male rats. Neuroimmunomodulation 2005; 12: 146-51.

[121] Ohdo S, Koyanagi S, Suyama H, et al. Changing the dosing schedule minimizes the disruptive effects of interferon on clock function. Nat Med 2001; 7: 356-60.

[122] Nava F, Carta G, Haynes LW. Lipopolysaccharide increases arginine-vasopressin release from rat suprachiasmatic nucleus slice cultures. Neuroscience Letters 2000; 288: 228-30.

[123] Sadki A, Bentivoglio M, Kristensson K, et al. Suppressors, receptors and effects of cytokines on the aging mouse biological clock. Neurobiol Aging 2007; 28: 296-305.

[124] Esquifino AI, Cano P, Jimenez-Ortega V, et al. Neuroendocrineimmune correlates of circadian physiology: studies in experimental models of arthritis, ethanol feeding, aging, social isolation, and calorie restriction. Endocrine 2007; 32 (1): 1-19.

[125] Rechtschaffen A, Bergmann BM, Everson CA, et al. Sleep deprivation in the rat: $\mathrm{X}$. Integration and discussion of the findings. Sleep 1989; 12: 68-87.

[126] Barriga-Ibars C, Rodriguez-Moratinos AB, Esteban S, et al. Interrelaciones entrel el sueño y el sistema inmune. Rev Neurol 2005; 40: 548-56.

[127] Pinsky MR. Sepsis: a pro- and anti-inflammatory disequilibrium syndrome. Contrib Nephrol 2001; (132): 354-66.

[128] Sriskandan S, Cohen J. The pathogenesis of septic shock. J Infect 1995; 30: 201-6.

[129] Calandra T, Cohen J. The international sepsis forum consensus conference on definitions of infection in the intensive care unit. Crit Care Med 2005; 33: 1538-48.

[130] Annane D, Bellissant E, Cavaillon JM. Septic shock. Lancet 2005; 365: 63-78 